\title{
Analyzing Judgment in Bipolar Depression Patients' Narratives Using Syntactic Patterns: A Corpus-Based Study
}

\author{
Muhammad S. Abdo*1, Amany Youssef**2, Nihal Nagi Sarhan*3 \\ * English Language Department, Faculty of Al-Alsun \\ ${ }^{* *}$ Department of English Language and Literature, Faculty of Arts \& Humanities, The British University in Egypt ${ }^{1}$ \\ 1Muhsabrys@outlook.com \\ 2amaniyoussefali@yahoo.com \\ 3Nihal_Nagi@alsun.asu.edu.eg
}

\begin{abstract}
For years, the Internet has provided patients with mental health disorders with several platforms where they share their personal experiences with their medical conditions. This study aims at exploring online narratives shared by patients with Bipolar Depression disorder where they self-report their medical diagnoses of the disorder and reflect on the hardships they go through in their lives. The study employs Martin and White's (2005) Appraisal Theory to examine the JUDGMENTS that patients make about their behaviors and the behaviors of people around them. In order to extract the JUDGMENT utterances from the corpus of narratives, the study uses syntactic patterns that may yield evaluative utterances. The results of the study show that judgments which belong to capacity [i.e., how (in)capable a person is] and propriety [i.e., how (un)ethical a person is] measure the highest scores among all other subtypes of JUDGMENT. The study also provides a lexicon for the most frequent expressions that convey JUDGMENT, which could be used to enrich the Appraisal resources.
\end{abstract}

Key words: Bipolar depression; Syntactic patterns; Psycholinguistics; Corpus linguistics

\section{INTRODUCTION}

BDD is an affective disorder that is characterized by extreme mood swings which range from euphoria to depression. These moods are indicated by loss of pleasure and reduced energy, and they can hinder patients from carrying out their daily tasks [1-5]. Previous studies have shown that mentally ill patients resort to Mental Health Forums (MHF) to recount their experiences with their diseases for several reasons. Some of these reasons are to fight the social stigma connected to mental illness, to find support, or to explain some of their behaviors [3,6]. Further, Pennebaker [5] believed that when patients write about their experiences with their diseases, it helps them heal and overcome their illnesses.

From a linguistic standpoint, the underlying assumption is that language can be indicative of a person's mental health. Hence, the linguistic choices that patients with mental disorders make would reveal significant insights about their disorders and its physical, psychological, and social manifestations [6-9]. De Martino [11] and Luno et al. [12] have studied ill narratives from a linguistic perspective. Within the framework of Martin and White's Appraisal Theory [10], De Martino [10] concluded that men were overwhelmed by the experience of illness and faced difficulty to adopt heroic attitudes.

The present study aims at examining the evaluative language in a vast collection of narratives by depressed individuals who suffer from Bipolar Depression Disorder (BDD) on MHF. More specifically, we focus on how these individuals reflect, in their narratives, on their own behavior and that of people around them based on Martin and White's Appraisal Theory [10], which deals with the different ways in which people make positive and negative attitudinal evaluations. More specifically, the study focuses on and extends one of the subsystems in Appraisal Theory, namely, judgement. Originally, judgement is concerned with how we construe "our attitudes to people and the way they behave - their character (how they measure up)," [10], i.e. other-evaluation. In the present study, JUDGEMENT is extended to how we/the patients view our/their own attitude and how we/they behave, i.e. self-evaluation.

This study aims at answering two main questions:

1- Which of the sub-types of JUDGMENT dominate(s) the narratives of Bipolar Disorder patients?

2- Which of the employed syntactic patterns help in generating JUDGEMENTAL utterances?

To avail the collection of corpus-based evidence, this study targets a number of syntactic patterns that are believed to reflect evaluative utterances. These patterns were firstly proposed by Bednarek [13], and later developed by Su [14] in an attempt to improve the automatic identification of attitudinal evaluations. The study also aims at providing a lexicon for each subtype in JUDGMENT in order to enrich the linguistic resources used in detecting this subsystem of appraisal.

This paper is organized into four sections. Section 2 covers the theoretical background of Appraisal Theory. Section 3 demonstrates the steps followed in creating the corpus of narratives, preprocessing the corpus, and the tools used in analysis. This section also defines the syntactic patterns used in this study. Section 4 views the results and representative samples of

\footnotetext{
${ }^{1}$ On secondment from the Faculty of Arts, Helwan University
} 
analysis of JUDGMENT before it discusses the findings. Section 5 draws the concluding remarks and defines the limitations of the present study.

\section{THEORETICAL BACKGROUND}

Appraisal Theory (AT), developed by Martin and White [10], is concerned with the subjective presence of writers in texts as they adopt stances both towards the material they present and towards those with whom they communicate. It is also concerned with how writers approve and disapprove, enthuse and abhor, applaud and criticize, and with how they urge their readers to react accordingly. Moreover, AT contributes to the analysis of those meanings by which texts convey positive or negative assessment [13-15]. One of the functions that AT performs is attitudinal positioning (referred to as attitude). In attitudinal positioning, AT is concerned with praising and blaming; that is, how writers and speakers communicate positive and negative evaluations of people, objects, and their own emotional reactions [10]. Attitude is divided into three subtypes which are all related to emotion [16]:

1- AFFECT: the area that covers personal emotional states (e.g., I feel embarrassed).

2- JUDGMENT: the positive and negative evaluations of people, their personalities, and behaviors (e.g., she is such an obnoxious person).

3- APPRECIATION: the aesthetic evaluation of things, texts, situations, and all what is inanimate (e.g., Yesterday's match was one of a kind!).

The subsystem of JUDGMENT, which is the focus of the present study, is divided into two types: judgments of social sanction and judgements of social esteem. On the one hand, judgments of social sanction refer to the rules and regulations set by the society. These may include legal, moral, and religious principles and obligations. On the other hand, judgments of social esteem include assessments under which the person being judged will be praised or condemned in the esteem of his/her community. However, unlike social sanction judgments, if the values of social esteem were violated, they would not be evaluated as sins or crimes [10]. Social sanction and social esteem subsystems are further divided into two and three subsystems, respectively, as shown in figure 1. Social esteem judgments are divided into:

- Normality: how un(usual) the judged person is (e.g., lucky, unfortunate).

- Tenacity: how resolute or dependable the person is (e.g., heroic, lazy).

- Capacity: how in(capable) the judged person is (e.g., smart, weak).

Social sanction judgments, as represented in figure 1, are divided into:

- Veracity: how truthful the person is (e.g., frank, dishonest).

- Propriety: how ethical judged person is (e.g., appropriate, immoral).

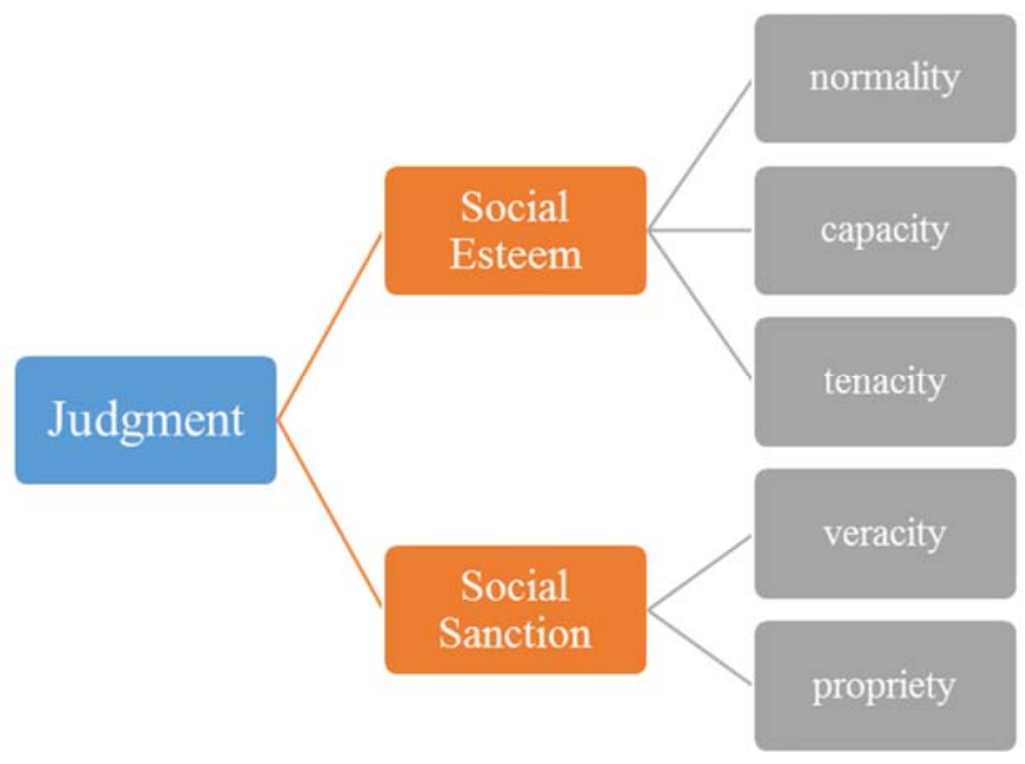

Figure 1. Judgment in Appraisal Theory adapted from Martin and White (2005, p.53) 


\section{MeTHOD}

We compiled a corpus from online mental health forums where patients openly write about their disorder. We included comments ONLY in which narrators reported their diagnosis with bipolar disorder. First, The corpus was preprocessed following a three-fold process: a) all contracted forms (i.e., we're, I'm) were converted into long forms for avoiding automatic (machinery) exclusion of such short forms (i.e., we are, I am); b) the common misspellings of pronouns (i.e., u, i) were replaced with their full spellings (i.e., you, I); and c) the common internet slang abbreviations (i.e., $b c$, w/, n) were substituted with their original spellings (i.e., because, with, and) to be processed correctly by Sketch Engine.

The corpus was then uploaded onto Sketch Engine, an online corpus analysis tool, to be syntactically parsed. Afterwards, we identified specific syntactic patterns in the corpus using Sketch Engine Concordance and downloaded all the generated results. For instance, Figure 2 displays a representative sample of the pattern "ADJ for" which is found to carry attitudinal evaluations. All sentences were manually annotated with the relevant sub-type of JUDGMENT. The total number of JUDGMENT instances was quantified in each pattern to measure patterns which had the most JUDGMENT annotations, and whether or not there could be any association between specific patterns and certain sub-types of JUDGMENT. The following section provides a detailed description of the corpus collection process.

identifying the person as stupid, incompetent or a therapist? Probably huh... I believe it is never me for the simple fact that I have been relatively relief just came crashing down on me. She has been It was for the best, trust me. My parents were no ke a different antidepressant this time, and to be ted to share their stories too! They told me I was

responsible for
right for
stable for
distant for
good for
alert for
brave for

their condition. Shame, fear, ignorance and anyone to take a life of another living breathing the better part of eight years. What never seems years, but I saw that she became even more so each other. But it started something in me that I possible signs of another manic swing. If you choosing to stay alive and care for myself and my

Figure 2. Concordance of the pattern "ADJ for"

\section{A. Corpus Description}

The corpus collection process in this study follows the methodology of Coppersmith et al. [6] who presented a novel way of acquiring mental health data using the self-identification technique proposed by Beller et al. [16]. We searched mental health forums for narratives that included the statement: "I * diagnosed with bipolar disorder." The asterisk sign was used to ensure all tenses (i.e., I am diagnosed, I was diagnosed, I have been diagnosed) are included in the results. All the URLs of the narratives we found were added to a text file and their body texts were downloaded using the software BootCat. BootCat helps its users create corpora using a list of URLs. It removes all the unnecessary text such as HTML tags, extracts text from the given URLs, and stores them in separate files [17]. All files were then merged into a larger file to be uploaded onto Sketch Engine. Table 1 stratifies the content words retrieved from the corpus ${ }^{2}$. The retrieved stratification is consistent with the conventional norms of using content words where nouns and verbs are the most frequently used categories.

TABLE 1: NUMBERS OF CONTENT WORDS IN THE STUDIED CORPUS

\begin{tabular}{|c|c|}
\hline Word Type & Frequency in Bipolar data \\
\hline Nouns & 322,167 \\
\hline Verbs & 324,674 \\
\hline Adjectives & 113,691 \\
\hline Adverbs & 118,735 \\
\hline $\begin{array}{c}\text { Total Number of } \\
\text { words }\end{array}$ & $1,581,533$ \\
\hline
\end{tabular}

\section{B. Syntactic Patterns}

To obtain utterances that convey JUDGMENT from the bipolar corpus, the online corpus tool "Corpus Query Language" was used to generate statements with a specific sequence of part-of-speech tags. For instance, to look for the pattern ADJECTIVE TO VERB (i.e., able to fight, young to understand), the following query is used: [tag ="J.*"] [word = "to" \& tag ="TO"] [tag ="VV"]. The Concordance tool should then display all the results that include this query as an encoded node, as shown in Figure 3. The total number of patterns used was 68 patterns; however, only 43 patterns were found in the corpus, where only 32 of these patterns included JUDGMENT evaluations. The list of patterns with examples is found in Appendix 1. All the symbols used for these patterns (e.g., JJ for adjectives, NN for nouns, VVG for gerunds) are taken from the Tree Tagger Tag Set, which is available at: https://courses.washington.edu/hypertxt/csar-v02/penntable.html.

\footnotetext{
2 The corpus used in the study can be freely accessed and downloaded through this link: https://drive.google.com/file/d/1ssDHLHQ1hIEFA5eTLQK2O1HsD7r5r0w2
} 


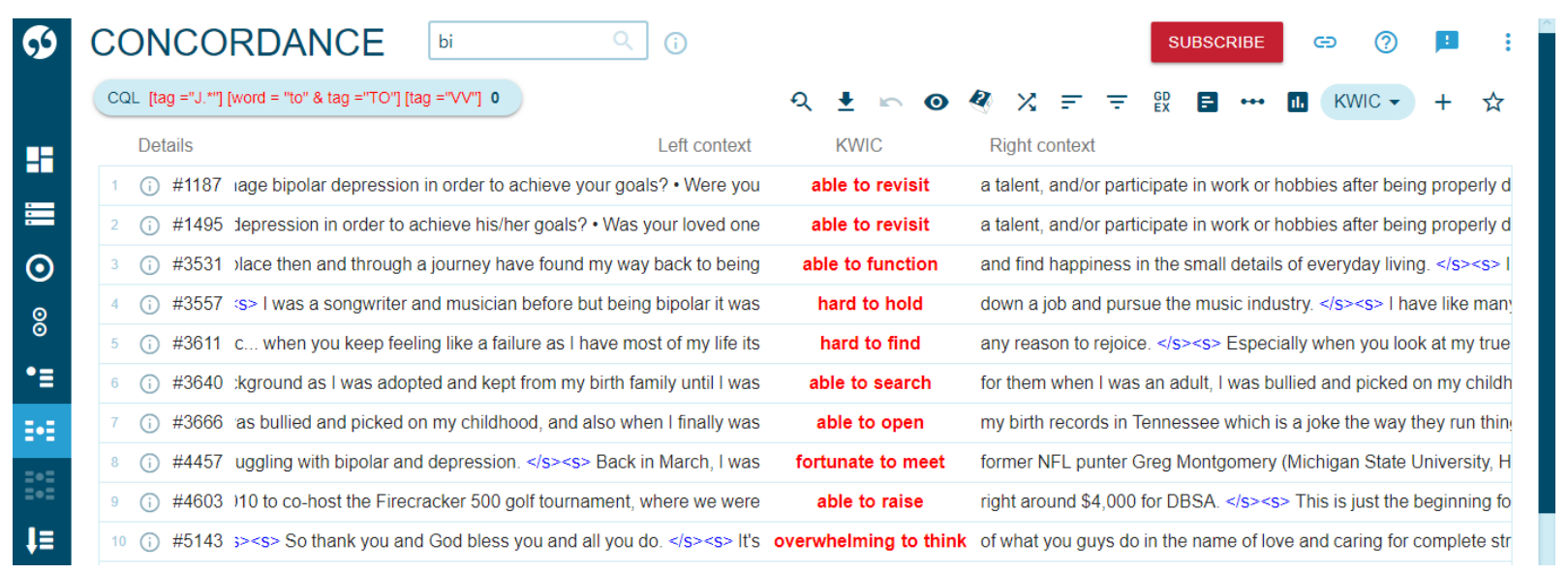

Figure 3. Concordance of inductive syntactic patterns

\section{Results AND Discussion}

The linguistic resources that Martin and White [10] provide in their introduction to AT are not the end products. Many of the most frequent expressions that imply evaluation in general and attitude in specific were revised. That is why, during the annotation process, encountering linguistic tokens (e.g., words/ expressions) that was not provided by Martin and White [10], necessitated looking for their synonyms and exploring similar annotations in previous studies. During the annotation, not only the patterns were observed, but also the context was taken into consideration in choosing the appropriate JUDGMENT sub-type. As shown in Figure 4, social esteem subsystem dominated the bipolar narratives with $81.4 \%$ of the total instances of JUDGMENT made by the patients versus $18.6 \%$ for social sanction judgments. The following two sections cover the results of the analysis in the sub-systems of social esteem and social sanction.

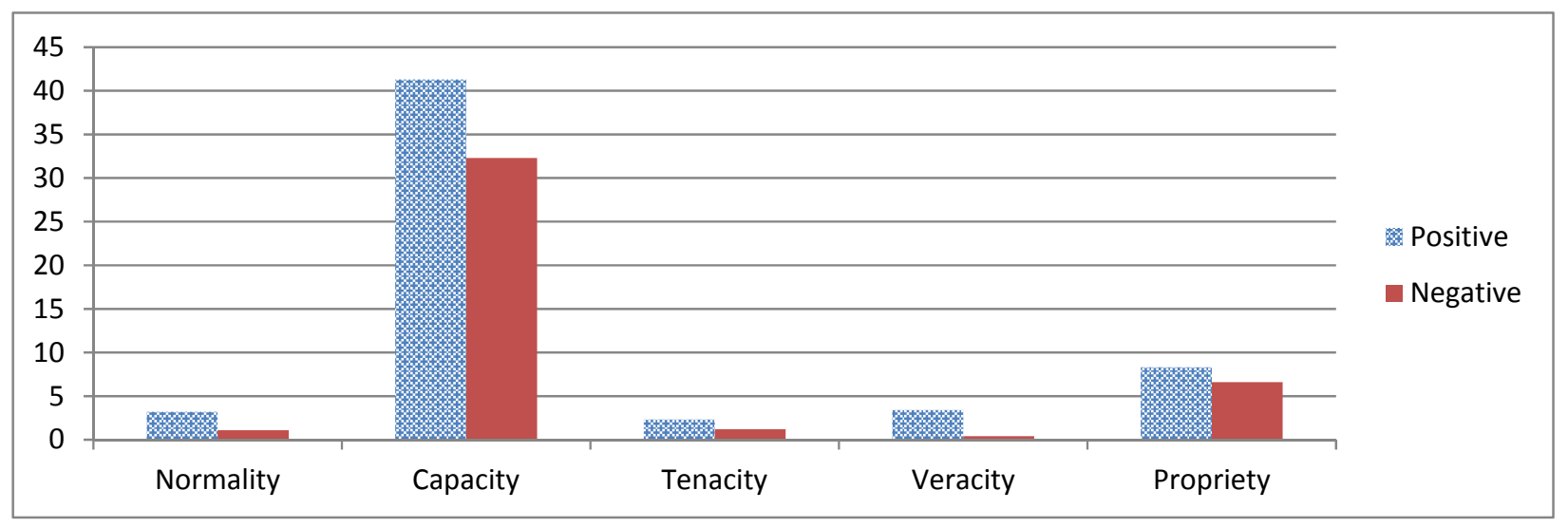

Figure 4. Representation of judgments percentages in the studied corpus

\section{A. Social esteem}

One of the significant findings of our analysis is detecting high frequency of the "positive capacity" sub-type in comparison with all the other sub-types. The capacity system represented $73.6 \%$ of the total instances of JUDGMENT with $41.3 \%$ for positive capacity and $32.3 \%$ for negative capacity. Figure 5 shows representative statements of both positive and negative capacity, from different patterns.

Appendix 2 defines the most frequent expressions that triggered capacity. Clearly, the majority of these expressions belong to particular semantic domains which are all, positive and negative, manifestations of capacity. Some of the positive domains are ability (e.g., able to, capable of), awareness (e.g., aware of, knowledgeable about, conscious that), vitality (e.g., active in, alive for), sobriety (e.g., sober for, clean from), and functionality (e.g., good at, successful in). The domains that were most common in negative evaluations are inability (e.g., unable to, vulnerable to), hesitation (e.g., reluctant to, hesitant to), sickness (e.g., bipolar at, sick with), and unawareness (e.g., ignorant of, unfamiliar with). 
when I have barely any anxiety and am to cancel my projects because I was too do so at the best of their abilities and are So sad but I am working on being more mental health mean people are largely okay, and made me feel safe. If I was able to

sick to skilled in mindful of ignorant of inexperienced with enjoy my life. I have dissociative problems when Capacity $(+)$ handle the stress. They said they had been there Capacity (-) what they do. Our friends and family may not Capacity $(+)$ how I word things as to not hurt anyone. If only I Capacity $(+)$ your actual situation. It was like living in a anxiety, this would have been my downfall.
Capacity (-)

Capacity (-)

\section{Figure 5. Annotation of both positive and negative capacity}

Unlike capacity, both normality and tenacity subsystems (figure 6) were not highly covered in the narratives corpus. Results show that the main positive semantic domains in normality are fortunateness (e.g., lucky to/ for, fortunate to/for), stability (e.g., stable for, regular with), and importance (e.g., important in, prominent in). Negative domains included unworthiness (e.g., unworthy of, undeserving of) and instability (e.g., unstable to, unusual for). With regard to TENACITY, caution (e.g., careful about, vigilant about), support (e.g., supportive of, dependent on), accountability (e.g., accountable for), and bravery (e.g., brave for) were the highest positive domains in frequency. Finally, the negative domains of tenacity included carelessness (e.g., reckless with, careless about), impatience (e.g., impatient to), and irresponsibility (e.g., irresponsible to). All the expressions that were annotated as social esteem are found in Appendix 2 and Appendix 3.

the first month, but was able to get it is intensifying my depression. I am She told me I am way too hey were bad parents. He was with bipolar disorder need to be extra During manic and depressed periods, be stable with fortunate that inconsistent as adamant that careful that cautious about med changes. For the past month I have I do not suffer from agoraphobia or any a human being and I need to get help. they were not disciplining me properly. it does not trigger a more extreme mood sharing what you have written because you
Normality $(+)$ Normality $(+)$ Normality (-) Tenacity (-) Tenacity $(+)$ Tenacity $(+)$

Figure 6. Annotation for NORMALITY and TENACITY

\section{B. Social Sanction}

The analysis shows that bipolar disorder patients pay considerable attention to whether a behavior is ethical or not more than the credibility of that behavior. Since the subtype of propriety represents approximately $14.9 \%$ of the total analysis versus $3.8 \%$ for veracity.

The major positive semantic domains that PROPRIETY (figure 7) included are appropriateness (e.g., nothing wrong with, appropriate for, welcome to), fairness (e.g., fair that, fair to), wisdom (e.g., wise to, wise for), patience (e.g., patient with), and decency (e.g., gentle with, appreciative of). The negative semantic domains included inappropriateness (e.g., something wrong with, something wrong in, inappropriate for), unfairness (e.g., unfair that, unfair to), and inflexibility (e.g., intolerant of, dismissive of).

our thoughts, feelings, and behaviors. It episodes themselves. So it would indeed to see my therapist anymore. I thought it if you are sufficiently trained, you know it I confronted this and she indicated this Kids were competitive and way too is fair to be appropriate to was ridiculous to is unethical to obsessive over aggressive for say that in general, social anxiety can create prescribe an antidepressant during depression be threatened like that, but I really was given provide professional advice without knowing men was part of the hypomania and it meant me to handle. I think something that I could
PROPRIETY $(+)$ PROPRIETY $(+)$ PROPRIETY (-) PROPRIETY (-) PROPRIETY (-) PROPRIETY (-)

\section{Figure 7. Annotation for propriety.}

Surprisingly, the ratio of utterances that express positive or negative veracity was low. Moreover, the linguistic resources used to express either positive or negative veracity are very limited compared to the other subtypes. The semantic domains which are represented in positive veracity are openness (e.g., open about, vocal about), and honesty (e.g., honest about, true that). With regard to the semantic domains of negative veracity, dishonesty (e.g., not honest with, not true that) is the only major semantic domain found. Appendix 3 shows all the expressions that were annotated as social sanction. 
on taking care of ourselves. I will be two times when I have been wholly If and when I do date, I will be going to these things if they were not and just had sex with have used me, I knew to be true turns out to be not honest with you. I lost myself somewhere along the authentic about my disorder with my students in the candid about being bipolar. Better to be rejected serious about you. He came to see me graduate after cheated on me (the relationships), mentally abused true at all. I have found that I only knew half
VERACITY $(+)$

VERACITY $(+)$

VERACITY $(+)$

VERACITY (-)

VERACITY (-)

VERACITY (-)

Figure 8. Annotation for veracity

As aforementioned, the study uses specific syntactic patterns that are believed to generate JUDGMENTAL evaluations. The analysis shows that the patterns [JJ to] as in "skilled in", [JJ to VB] as in "able to adapt", [VB JJ to] as in "was fortunate to", and [JJ with] as in "dishonest with" are the top three lucrative structures that help detect JUDGEMENTS. Interestingly, this applies to both positive and negative JUDGMENTS. Detailed description of the 32 patterns and the number of JUDGMENTS they generated is found in Appendix 1.

Obviously, our findings go hand in hand with the relevant corpus-based studies which promote corpus tools as effective in applying syntactic patterns to retrieve attitudinal evaluations [6-7]. Although this evidence is not solid enough to claim that bipolar patients have predilection to using specific syntactic patterns different from that in normal population, our study suggests that this syntactic specificity in bipolar patients remains possible should other neurolinguistics experiments explore this thread further. However, Raucher-Chéné et al. [17] demonstrate in their systematic review and meta-analysis, that BDD patients demonstrate a remarkable structural alternation and unusual affective use of language especially at the semantic level and abnormal prosody.

\section{Conclusions}

This study aims at identifying the dominant sub-types of JUDGMENT in the narratives of Bipolar Disorder patients. The capacity system represents $73.6 \%$ of the total instances of JUDGMENT with $41.3 \%$ for positive capacity and $32.3 \%$ for negative capacity. At the fourth quartile, propriety and veracity follow capacity. At the affective level, positivity of JUDGMENT subsystems is generally higher than negativity. For evaluating the validity of using syntactic patterns in generating JUDGEMENTAL utterances, $\mathrm{J} *$ to, $\mathrm{J} *$ to $\mathrm{VB}, \mathrm{VB} * \mathrm{~J} *$ to, $\mathrm{J} *$ with, $\mathrm{J} *$ in, $\mathrm{J} *$ for, $\mathrm{J} *$ of, $\mathrm{J} *$ about, $\mathrm{J} *$ at, $\mathrm{J} *$ that, $\mathrm{J} *$ as, and $\mathrm{J}^{*}$ on, prove to be the most inductive syntactic patterns in our study. Limitations of the present study included the relatively small-sized corpus and reliability of self-reported written narratives in reflecting the linguistic and affective changes bipolar patients suffer. However, studying these variables at several settings and at larger-scale specialized corpora should help to generalize our findings.

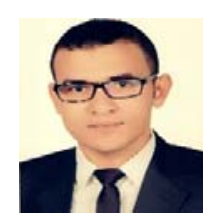

\section{BIOGRAPHY}

Muhammad S. Abdo is an MA candidate at Al-Alsun, Ain Shams University, Cairo, EGYPT. He is also an English language teacher at the English Language Resource Centre (ELRC) at Al-Azhar University, and at AMIDEAST Egypt.

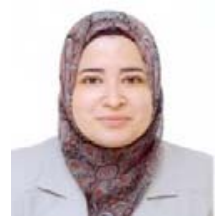

Amany Youssef is Associate Professor of linguistics at the Department of English Language and Literature, Faculty of Arts \& Humanities, the British University in Egypt, on secondment from Helwan University. Her research interests include syntax, metadiscourse, discourse analysis and semiotics.

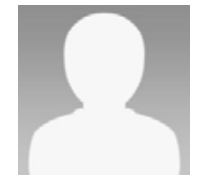

Nihal Nagi Sarhan is Lecturer in linguistics at Al-Alsun, Ain Shams University, Cairo, EGYPT. Sarhan's research interests include contrastive linguistics and sociolinguistics. 


\section{REFERENCES}

[1] National Institute of Mental Health (2016). Bipolar Disorder. Retrieved February 20, 2019, from https://www.nimh.nih.gov/health/topics/bipolar-disorder/index.shtml

[2] Sklar, P., Gabriel, S. B., McInnis, M. G., Bennett, P., Lim, Y.-M., Tsan, G., ... Lander, E. S. (2002). Family-based association study of 76 candidate genes in bipolar disorder: BDNF is a potential risk locus. Molecular Psychiatry, 7(6), 579-593. doi:10.1038/sj.mp.4001058

[3] Phillips, M. L., \& Kupfer, D. J. (2013). Bipolar disorder diagnosis: challenges and future directions. The Lancet, 381(9878), 1663-1671. doi:10.1016/s0140-6736(13)60989-7

[4] Ramirez-Esparza, N., Chung, C. K., Kacewicz, E., \& Pennebaker, J. W. (2008, March). The Psychology of Word Use in Depression Forums in English and in Spanish: Texting Two Text Analytic Approaches. In ICWSM.

[5] Pennebaker, J. W. (2011). The secret life of pronouns. New Scientist, 211(2828), 42-45.

[6] Coppersmith, G., Dredze, M., Harman, C., \& Hollingshead, K. (2015). From ADHD to SAD: Analyzing the Language of Mental Health on Twitter through Self-Reported Diagnoses. Proceedings of the 2nd Workshop on Computational Linguistics and Clinical Psychology: From Linguistic Signal to Clinical Reality.

[7] Reece, A. G., Reagan, A. J., Lix, K. L. M., Dodds, P. S., Danforth, C. M., \& Langer, E. J. (2017). Forecasting the onset and course of mental illness with Twitter data. Scientific Reports, 7(1).

[8] Eichstaedt, J. C., Smith, R. J., Merchant, R. M., Ungar, L. H., Crutchley, P., Preoţiuc-Pietro, D., ... Schwartz, H. A. (2018). Facebook language predicts depression in medical records. Proceedings of the National Academy of Sciences, 115(44), 11203-11208.

[9] Guntuku, S. C., Yaden, D. B., Kern, M. L., Ungar, L. H., \& Eichstaedt, J. C. (2017). Detecting depression and mental illness on social media: an integrative review. Current Opinion in Behavioral Sciences, 18, 43-49. doi:10.1016/j.cobeha.2017.07.005

[10] Martin, J. R., \& White, P. R. R. (2005). The Language of Evaluation. Appraisal in English. Palgrave Macmillan

[11] De Martino, M (2001), "Illness narratives: a linguistic study of gender and identity in patients' accounts", available at: http://www.fedoa.unina.it/9000/1/de_martino_marco_24.pdf (accessed 12 March 2019).

[12] Luno, J. A., Max Louwerse, and J. Gayle Beck. "Tell us your story: Investigating the linguistic features of trauma narrative." In Proceedings of the Annual Meeting of the Cognitive Science Society, vol. 35, no. 35. 2013.

[13] Bednarek, M. (2009). Language patterns and ATTITUDE. Functions of Language, 16(2), 165-192.

[14] $\mathrm{Su}, \mathrm{H}$. (2015). Judgement and adjective complementation patterns in biographical discourse: a corpus study (Doctoral dissertation, University of Birmingham).

[15] Read, J., \& Carroll, J. (2010). Annotating expressions of Appraisal in English. Language Resources And Evaluation, 46(3), 421-447.

[16] Beller, C., Knowles, R., Harman, C., Bergsma, S., Mitchell, M., \& Van Durme, B. (2014). I'm a Belieber: Social Roles via Self-identification and Conceptual Attributes. Proceedings of the 52nd Annual Meeting of the Association for Computational Linguistics (Volume 2: Short Papers).

[17] Baroni, M., \& Bernardini, S. (2004, May). BootCaT: Bootstrapping Corpora and Terms from the Web. In LREC (p. 1313).

[18] White, P. R. R. (2015). Appraisal Theory. The International Encyclopedia of Language and Social Interaction, 1-7.

[19] Raucher-Chéné, Delphine, Amélie M. Achim, Arthur Kaladjian, and Chrystel Besche-Richard. "Verbal fluency in bipolar disorders: a systematic review and meta-analysis." Journal of affective disorders 207 (2017): 359-366. 
Appendix 1: A list of the syntactic patterns that were successful in generating JUDGMENT and their percentages.

\begin{tabular}{|c|c|c|}
\hline Syntactic Patterns & Examples & The percentage in the corpus \\
\hline $\mathrm{J} *$ to & rude to & $25.22 \%$ \\
\hline $\mathrm{J} *$ to $\mathrm{VB}$ & unethical to provide & $22.4 \%$ \\
\hline $\mathrm{VB} * \mathrm{~J} *$ to & was lucky to & $17.10 \%$ \\
\hline J* with & honest with & $6.40 \%$ \\
\hline $\mathrm{J} *$ in & abusive in & $4.48 \%$ \\
\hline $\mathrm{J}^{*}$ for & aggressive for & $4.01 \%$ \\
\hline $\mathrm{J}^{*}$ of & Guilty of & $2.96 \%$ \\
\hline $\mathrm{J}^{*}$ about & indifferent about & $2.96 \%$ \\
\hline $\mathrm{J}^{*}$ at & Brutal at & $2.90 \%$ \\
\hline $\mathrm{J} *$ that & Impulsive that & $1.92 \%$ \\
\hline $\mathrm{J} *$ as & disrespectful as & $1.61 \%$ \\
\hline $\mathrm{J}^{*}$ on & Discriminatory on & $1.61 \%$ \\
\hline $\mathrm{J} * \mathrm{WRB}$ & Harsh when & $1.41 \%$ \\
\hline VB* J* that & Is wrong that & $0.99 \%$ \\
\hline $\mathrm{J} *$ from & Abusive from & $0.95 \%$ \\
\hline it $\mathrm{V}^{*} \mathrm{~J} *$ to $\mathrm{VB}$ & it feels wrong to do & $0.58 \%$ \\
\hline There VB* NN J* with & there is something wrong with & $0.54 \%$ \\
\hline It $\mathrm{VB}^{*} \mathrm{~J} *$ to $\mathrm{VB}$ & it was wrong to discriminate & $0.54 \%$ \\
\hline J* by & childless by & $0.49 \%$ \\
\hline It $\mathrm{VB}^{*} \mathrm{~J} *$ that & it is wrong that & $0.15 \%$ \\
\hline $\mathrm{J} *$ towards & bad towards & $0.12 \%$ \\
\hline $\mathrm{J} *$ over & Obsessive over & $0.08 \%$ \\
\hline It $\mathrm{VB}^{*} \mathrm{~J} *$ for $*$ to & it is acceptable for me to & $0.08 \%$ \\
\hline $\begin{array}{c}\text { It VB* J* if } \\
\text { (OR) It VB* WRB } \\
\text { (OR) It VB* WP }\end{array}$ & it was $\mathrm{OK}$ if & $0.08 \%$ \\
\hline $\mathrm{J} *$ as to & patient as to & $0.07 \%$ \\
\hline it $\mathrm{VB}^{*} \mathrm{~J}^{*}$ if & it was $\mathrm{OK}$ if & $0.07 \%$ \\
\hline $\mathrm{V} *$ it $\mathrm{J} *$ to $\mathrm{VB}$ & Is it selfish to enjoy & $0.07 \%$ \\
\hline There VB* NN J* about & there was something wrong about & $0.03 \%$ \\
\hline It $\mathrm{VB}^{*} * \mathrm{~J} *$ that & it is not true that & $0.03 \%$ \\
\hline there $\mathrm{VB}^{*} * \mathrm{~J} *$ in & there is a moral in & $0.03 \%$ \\
\hline $\begin{array}{c}\mathrm{J}^{*} \text { as to WRB } \\
(\mathrm{OR}) \mathrm{J}^{*} \text { as to WP }\end{array}$ & cautious as to what & $0.03 \%$ \\
\hline
\end{tabular}


Appendix 2: Expressions that were annotated as subtypes of SOCIAL ESTEEM

\begin{tabular}{|c|c|}
\hline \multicolumn{2}{|r|}{ CAPACITY } \\
\hline Positive & Negative \\
\hline $\begin{array}{l}\text { able in, able to, active in, active on, active with, adept at, } \\
\text { alert for, alive at, alive by, alive for, asymptomatic for, } \\
\text { athletic to, aware that, awesome at, be ready to, best at, } \\
\text { best to, better at, better for, better in, better over, better to, } \\
\text { better with, big for, brave in, cancer-free for, capable of, } \\
\text { careful of, clean for, clean from, clean in, clean of, clear of, } \\
\text { cognizant of, conscious about, conscious that, creative } \\
\text { about, creative in, creative that, creative with, efficient at, } \\
\text { energetic to, energetic with, episode-free for, equipped to, } \\
\text { euthymic for, excellent at, expert on, expressive with, } \\
\text { familiar with, fantastic in, faster at, fine in, fine to, firm in, } \\
\text { free for, free in, functional at, functional in, gifted as, good } \\
\text { as, good at, good for, good in, great at, great in, greater in, } \\
\text { hard as, hard on, hard that, hard to, hardest to, higher on, } \\
\text { highest on, hyperactive at, incredible at, independent as, } \\
\text { insightful about, insightful over, ready to, knowledgeable } \\
\text { about, mindful of, more in, new to, nondisabled to, } \\
\text { nonexistent for, okay for, okay in, perfect at, perfect in, } \\
\text { potent in, potential to, powerless in, proactive about, } \\
\text { proactive in, proactive with, productive at, productive in, } \\
\text { productive on, productive with, professional about, } \\
\text { professional as, professional in, professional over, } \\
\text { professional with, prolific as, psychosis-free for, quick on, } \\
\text { quiet on, ready by, ready with, responsive to, rid of, sane } \\
\text { about, self-conscious about, self-conscious in, sensible as, } \\
\text { skilled at, skilled in, skilled on, skillful at, smart in, sober } \\
\text { at, sober for, sober in, sober with, steadfast in, strong } \\
\text { about, strong as, strong for, strong in, stronger in, stronger } \\
\text { to, successful in, successful at, successful with, symptom- } \\
\text { free as, symptom-free for, talented of, treated in, } \\
\text { unconscious with, understandable to, valedictorian of, } \\
\text { weak for, well-adjusted for, well-aware that, well-educated } \\
\text { on, well-read on, young to. }\end{array}$ & 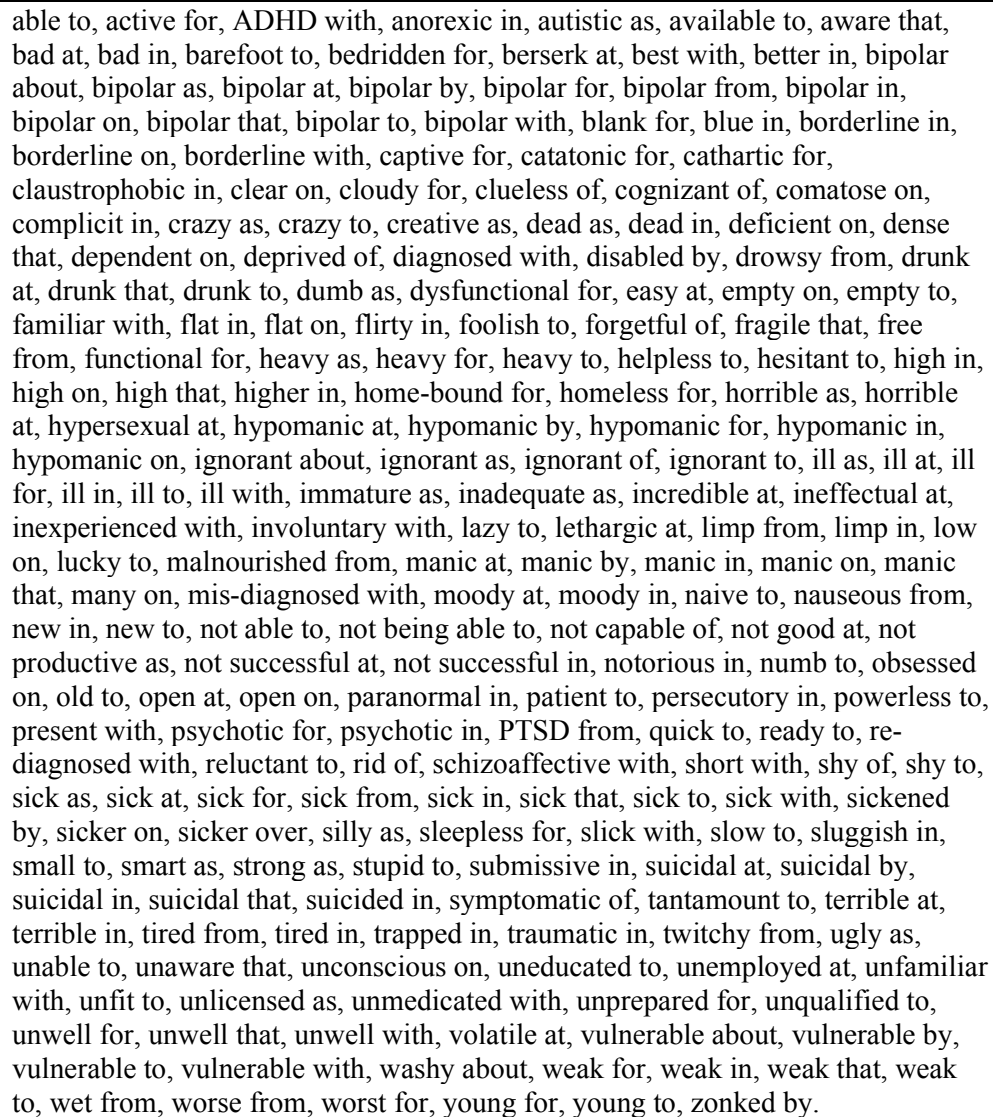 \\
\hline
\end{tabular}

\begin{tabular}{|c|c|}
\hline \multicolumn{2}{|l|}{ Tenacity } \\
\hline Positive & Negative \\
\hline $\begin{array}{l}\text { accountable for, accountable on, available when, awesome in, brave for, careful about, } \\
\text { careful from, careful of, careful that, careful to, careful when, careful with, care-taking } \\
\text { of, cautious about, cautious as, cautious as to, cautious when, cautious with, chief of, } \\
\text { clicked with, close for, compliant with, conscious to, conservative with, dedicated to, } \\
\text { dependent on, easy to, empathetic to, engaging with, ever-present on, ever-vigilant of, go } \\
\text { to, good for, good on, good to, hyper-vigilant about, mature for, most in, natural to count } \\
\text { on, open for, open to, patient as, professional for, professional to, promising at, } \\
\text { promising to, psychiatric for, responsive as, responsive when, smart to, sociable with, } \\
\text { social when, super-vigilant about, supportive as, supportive of, supportive when, } \\
\text { supportive with, thorough in, vigilant about, vigilant as, vigilant for, vigilant of, vigilant } \\
\text { with, wiser as. }\end{array}$ & $\begin{array}{l}\text { adamant that, remiss to, busy to, careless about, } \\
\text { codependent for, codependent on, crazy from, } \\
\text { distant for, distant whenever, good as, good for, } \\
\text { impatient to, impulsive when, irresponsible to, late } \\
\text { for, lax with, lazy with, negative as, not available at, } \\
\text { not careful with, not caring when, not compliant } \\
\text { with, not helpful at, not supportive of, quick to, } \\
\text { ready to, reckless with, remiss to, resistant to, slow } \\
\text { to, stubborn in, wise in. }\end{array}$ \\
\hline
\end{tabular}

\begin{tabular}{|c|c|}
\hline \multicolumn{2}{|l|}{ Normality } \\
\hline Positive & Negative \\
\hline $\begin{array}{l}\text { amazing as, beautiful of, calm as, clear as, clear on, clear-headed as, coherent for, } \\
\text { concise in, desirable to, direct in, engaging in, fortunate in, fortunate that, fortunate } \\
\text { to, friendly with, genuine in, important in, liberal in, lucky as, Lucky for, lucky in, } \\
\text { lucky on, lucky that, lucky to, lucky with, magnificent as, methodical when, nice as, } \\
\text { normal as, normal at, normal for, normal when, patient as to, prominent in, radiant } \\
\text { by, reasonable for, regular at, regular with, smart to, social in, something special } \\
\text { about, stable at, stable by, stable for, stable in, stable on, stable over, stable when, } \\
\text { stable with, strange at, super-stable for, sweet as, unique in, unstable at, well-known } \\
\text { in, wonderful in, worth that, worth trying. }\end{array}$ & $\begin{array}{l}\text { attractive as, awkward for, clear as, cool as, crazy for, } \\
\text { different as, different from, different in, different of, } \\
\text { different when, different where, distant at, eccentric at, } \\
\text { good for, in denial as to, inconsistent as, invisible for, } \\
\text { not social at, not social in, not stable on, notorious for, } \\
\text { old to, sensitive as, separated from, silly to, undeserving } \\
\text { of, unemployed for, unfortunate in, unreasonable with, } \\
\text { unresponsive from, unstable at, unstable to, unstable } \\
\text { with, unusual for, unworthy of. }\end{array}$ \\
\hline
\end{tabular}


Appendix 3: Expressions that were annotated as subtypes of SOCIAL SANCTION

\begin{tabular}{|c|c|}
\hline \multicolumn{2}{|c|}{ Propriety } \\
\hline Positive & Negative \\
\hline $\begin{array}{l}\text { a moral in, acceptable for, acceptable for me to, accountable of, } \\
\text { anything wrong with, appreciative of, appropriate for, appropriate to, } \\
\text { appropriate to listen, appropriate when, considerate of, correct in, } \\
\text { eligible for, engaging in, fair on, fair that, fair to, fine to, free to, } \\
\text { generous about, generous when, generous with, gentle on, gentle to, } \\
\text { gentle with, justifiable to, justified for, kind as to, malicious when, } \\
\text { moral of, nice about, normal about, normal to, nothing wrong with, } \\
\text { ok for, ok if, ok that,, ok to , on-track to, patient with, peaceful about, } \\
\text { permissive when, polite about, polite for, proper in, protective of, } \\
\text { reasonable to, respectful of, responsible about, responsible by, } \\
\text { responsible for, responsible with, right about, right for, right that, } \\
\text { right to, right to, right where, sensible at, sensible on, sensitive at, } \\
\text { sensitive in, soft with, some good in, something wrong with, strict } \\
\text { with, subtle in, tolerant of, welcome to, wise for, wise to, wise with, } \\
\text { wrong for, wrong in, wrong on, wrong with. }\end{array}$ & $\begin{array}{l}\text { absurd when, abusive from, abusive in, abusive towards, abusive when, } \\
\text { adamant about, aggressive as, aggressive for, aggressive in, aggressive } \\
\text { over, aggressive towards, aggressive when, appropriate for, are wrong } \\
\text { to, argumentative with, arrogant for, awkward when, bad as, bad of, } \\
\text { bad to, bad towards, belligerent when, best in, bitchy at, bitter about, } \\
\text { bitter towards, blatant with, blunt with, brutal at, callous at, childish } \\
\text { when, childless by, condescending about, confrontational with, crazy } \\
\text { in, crazy on, criminal to, critical of, defensive in, delusional about, } \\
\text { delusional in, delusional that, dependent in, discriminatory on, } \\
\text { disgusting when, dismissive of, disrespectful as, engaging in, foolish to, } \\
\text { forceful in, forceful that, fussy about, good for, great of, guilty for, } \\
\text { guilty of, hard on, harsh on, harsh when, harsh with, hateful towards, } \\
\text { homicidal in, hostile even from, hostile towards, hyper-focused on, } \\
\text { impatient with, impulsive by, impulsive that, inappropriate for, } \\
\text { inconsiderate of, inconvenient to, indifferent about, indifferent towards, } \\
\text { insulting about, intense in, intolerant of, intolerant when, irresponsible } \\
\text { for, irresponsible with, jealous over, judgmental of, messy from, naive } \\
\text { to, naked in, negative with, not fair for, not fair of, not fair on, not fair } \\
\text { that, not fair to, not good with, not okay to, not polite to, not reasonable } \\
\text { that, obsessive over, offensive to, old to, pedantic in, promiscuous with, } \\
\text { quick to, reckless in, responsible for, ridiculous to, right about, right } \\
\text { for, right that, right to, right when, rigid when, rude in, rude to, rude } \\
\text { when, scornful about, selfish by, selfish for, selfish of, selfish to, } \\
\text { snappy with, snarky when, sneaky that, snippy at, some vice in, } \\
\text { something wrong with, stingy about, stupid when, taboo of, terrible of, } \\
\text { tight with, unacceptable as, unapologetic about, unbearable in, } \\
\text { unethical to, unfair of, unfair that, unfair to, unreasonable to, vice of, } \\
\text { violent in, violent with, wild in, wrong about, wrong as, wrong by, } \\
\text { wrong in, wrong of, wrong on, wrong that, wrong to, wrong when, } \\
\text { wrong with. }\end{array}$ \\
\hline
\end{tabular}

\begin{tabular}{|c|c|}
\hline \multicolumn{2}{|c|}{ Veracity } \\
\hline Positive & Negative \\
\hline $\begin{array}{l}\text { true for, clean with, front with, honest with, true with, truthful with, } \\
\text { honest in, legal in, moral in, religious in, true in, true that, authentic } \\
\text { about, candid about, clean about, clear about, honest about, open about, } \\
\text { public about, realistic about, serious about, truthful about, vocal about, } \\
\text { honest when, true when, honest on, straight-up on, it is true that, it was } \\
\text { true that, is true that, was true that, true from, honest as, }\end{array}$ & $\begin{array}{l}\text { cheated on, checked on, not honest with, illegal where, not serious } \\
\text { about, not accurate to, not explicit about, not honest as, not true at, not } \\
\text { true for, not true in, not true that, }\end{array}$ \\
\hline
\end{tabular}




\title{
Arabic Abstract
}

\section{دراسة مسوغات الحكم في روايات مرضى الاكتئاب ثنائي القطب باستخدام تحليل الأنماط النحوية: دراسة ذخائرية}

\author{
"محمد صبري عبدها، **أماني بوسف2 ، *نهال ناجي سرحان3

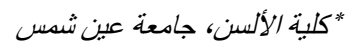

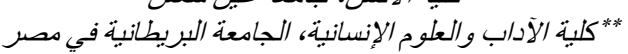 \\ 1Muhsabrys@outlook.com \\ 2amaniyoussefali@yahoo.com \\ 3Nihal_Nagi@alsun.asu.edu.eg
}

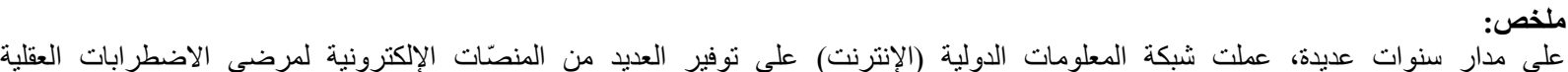

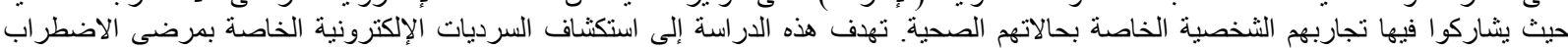

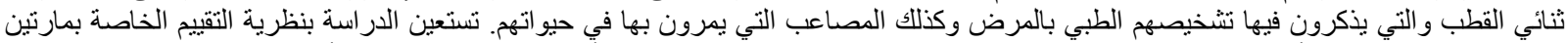

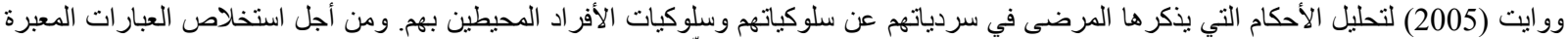

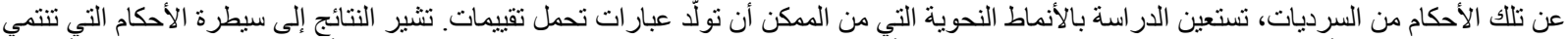

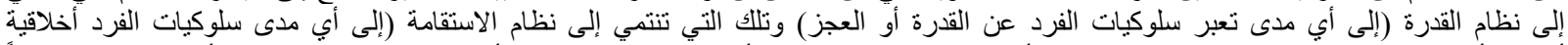

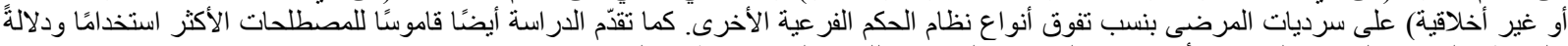

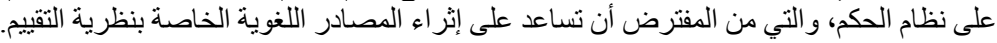

الكلمات المفتاحية:

الاكتئاب ثنائي القطب. الأنماط النحوية، علم اللغة النفسي. اللغويات الذخائرية.
\end{abstract}

